\title{
PERVIVENCIAS ESCOLARES DE NARRATIVA NACIONAL ESPAÑOLA: RECONQUISTA, REYES CATÓLICOS E IMPERIO EN LIBROS DE TEXTO DE HISTORIA Y EN RELATOS DE ESTUDIANTES*
}

\author{
Spanish national narrative in secondary education: Reconquest, \\ Catholic Monarchs and Empire in history textbooks and students' \\ accounts
}

\section{Jorge Sáiz Serrano ${ }^{\varnothing}$}

Fecha de recepción: 05/09/2016 • Fecha de aceptación: 25/11/2016

Resumen: Este trabajo examina las pervivencias de una narrativa maestra sobre la historia de España, como narrativa nacional, en libros de texto de historia en secundaria entre 1976 y 2016, y en actuales relatos históricos de estudiantes y docentes en formación. El marco de observación son tres hitos de dicha narrativa maestra (la Reconquista, el reinado de los Reyes Católicos y el imperio español) que perduran en los manuales. Es un estudio empírico, exploratorio y descriptivo basado en el análisis del discurso sobre una muestra probabilística de ejemplares de libros de texto de historia. Se compara este examen con resultados de investigaciones sobre relatos escolares de historia de España realizados por estudiantes y futuros docentes. Se analiza el discurso, en sus contenidos y formas, buscando evidenciar en qué medida los cambios políticos, educativos e historiográficos entre la Transición y la actualidad, han transformado la representación escolar de dichos contenidos. Los resultados muestran una dualidad entre libros de texto y narrativas de adolescentes y jóvenes. Por un lado vemos cambios significativos en los manuales escolares que impugnan explícitamente la dimensión esencialista; pero también vemos continuidades al conservar el hilo discursivo de la narrativa maestra (reconquista-unidad-imperio) reforzada con cartografía que individualiza «España» desde el siglo XVI y con imágenes de pintura histórica nacional del siglo XIX.

\footnotetext{
Este artículo ha contado con financiación de los proyectos de investigación EDU2015-65621-C3-1-R del Plan Nacional de I+D+i (MINECO, del Gobierno de España), del proyecto I+D de la Generalitat Valenciana (GV/2016/112) así como de la red de excelencia Red14 (Plan Estatal de Investigación 2013-2016).

ø Universidad de Valencia, Facultad de Magisterio, Departamento de Didáctica de las Ciencias Experimentales y Sociales, Avda. Tarongers, 4, 46022, Valencia. jorge.saiz@uv.es.
}

Cómo citar este artículo: Sáiz Serrano, Jorge. «Pervivencias escolares de narrativa nacional española: Reconquista, Reyes Católicos e Imperio en libros de texto de historia y en relatos de estudiantes», Historia y Memoria de la Educación, 6 (2017): 165-201. 
Por otro lado se constata la continuidad, entre adolescentes y jóvenes, de representaciones esencialistas y tradicionales de dichos contenidos. Todo ello derivaría de la débil educación histórica existente y la pervivencia de una narrativa nacional en usos sociales no escolares del pasado histórico.

Palabras clave: Libros de texto de historia; Narrativa nacional; Narrativas históricas de estudiantes; Educación secundaria; Historia de España.

Abstract. This paper examines the survival of a master narrative about the history of Spain, a national narrative as it is reflected in history textbooks in secondary education between 1976 and 2016 and in current historical accounts of students and teachers-in-training. The aim is to analyze three subjects of this master narrative (the Reconquest, the Catholic Monarchs and the Spanish Empire) that continue to have their place in history textbooks. We analyze the contents and forms of discourse with this aim: to demonstrate to what extent the political, educational and historiographical changes have transformed the national historical representation of such contents as a national discourse. This is an empirical, exploratory and descriptive study based on discourse analysis using a probability sample from history textbooks. This analysis is then compared with studies on historical accounts of Spain given by students and teachers-in-training. The results show a duality between textbooks and historical accounts of adolescents and youth. On the one hand, we see significant changes in academic texts from school textbooks without an essentialist national dimension; but we also see continuity in the discursive thread of the master narrative (reconquest-unit-empire), and with maps of "Spain» from the $16^{\text {th }}$ century and with images of national historical painting from the nineteenth century. On the other hand, we can see the continuity of essentialist and traditional representations of such contents in historical accounts of students and teachers-in-training. This is due principally to poor historical literacy in secondary education and the survival of a national master narrative in non-school social uses of the national historical past.

Keywords: History textbooks; National narrative; Students' historical accounts; Secondary education; History of Spain.

\section{INTRODUCCIÓN}

Este trabajo se inscribe en la línea del estudio de contenido de manuales escolares de historia, considerándolos como poderosos instrumentos de mediación cultural y construcción identitaria. ${ }^{1}$ De las perspectivas de

\footnotetext{
${ }^{1}$ Eckhardt Fuchs, «Currents trends in History and Social Studies Textbook Research» Journal of International Cooperation in Education, 14 (2), (2011): 17 -34; Maria Repoussi y Nicole Tutiaux-Guillon,
} 
investigación en manuales escolares ${ }^{2}$ y en manuales de historia escolar en concreto, este estudio asume la tradición crítica en análisis de libros de texto de historia que examina las relaciones entre ideología, identidad nacional y contenido de los manuales. ${ }^{3}$ Nos interesa el examen en manuales españoles de historia en educación secundaria de los últimos cuarenta años, de las páginas que dedican a unos contenidos históricos que aquí consideramos clave en la narrativa maestra tradicional del pasado de España, como representación nacionalizada del mismo: la Reconquista, el reinado de los Reyes Católicos y el imperio de los Austrias.

El objetivo es analizar el contenido y la forma del discurso histórico en los manuales escolares, una vía de investigación en historiografía escolar que ya cuenta con una tradición previa, ${ }^{4}$ paralela a la que se ocupa de la dimensión propiamente pedagógica y didáctica de los manuales. ${ }^{5}$ Como complemento del examen de manuales escolares, este artículo también recoge resultados de investigaciones sobre narrativas o relatos escolares de síntesis de historia de España realizados por estudiantes que finalizan secundaria y por profesores de historia en formación. ${ }^{6}$ Nos interesa una visión comparada del discurso histórico de los manuales y

«New Trends in History Textbook Research. Issues and Methodologies toward a School Historiography», Journal of Educational Media, Memory and Society 2 (1), (2010): 154-170.

${ }^{2}$ Falk Pingel, UNESCO Guidebook on Textbook Research and Textbook Revision (Paris y Braunschweig: Unesco \& Georg-Eckert-Institut, 2010).

${ }^{3}$ Stuart Foster, «Dominant Traditions in International Textbook Research and Revision», Education Inquiry, 2 (1), (2011): 11; Stuart Foster y Keith Crawford (eds.), What Shall We Tell the Children? International Perspectives on School History Textbooks (Greenwich. Connecticut: IAP, 2006).

${ }^{4}$ Rafael Valls, Historiografía escolar española: siglos XIX-XXI (Madrid: UNED, 2007).

${ }^{5}$ Rafael Valls, La enseñanza de la Historia y textos escolares (Buenos Aires: Zorzal, 2008); Jorge Sáiz, "Actividades de libros de texto de Historia, competencias básicas y destrezas cognitivas, una difícil relación: análisis de manuales de $10^{\circ}$ y $2 .^{\circ}$ de ESO ", Didáctica de las Ciencias Experimentales y Sociales, 25 (2011): 37-64, y «Alfabetización histórica y competencias básicas en libros de texto de historia y en aprendizaje de los estudiantes», Didáctica de las Ciencias Experimentales y Sociales, 27 (2012): 43-66.

${ }^{6}$ Jorge Sáiz, Educación histórica y narrativa nacional (Tesis doctoral, Universidad de Valencia, 2015); Jorge Sáiz y Ramón López Facal, «Competencias y narrativas históricas. El pensamiento histórico de estudiantes y futuros profesores», Revista de Estudios Sociales, 52 (2015): 87-101; Jorge Sáiz y Neus Colomer, «La historia moderna peninsular en narrativas de estudiantes al finalizar la ESO», en $\mathrm{La}$ Edad Moderna en Educación Secundaria. Experiencias de investigación, eds. Francisco García, Cosme J. Gómez y Raimundo Rodríguez (Murcia: Editum, 2016), 155-167; Jorge Sáiz y Ramón López Facal, «Narrativas nacionales históricas de estudiantes y profesorado en formación», Revista de Educación, 374 (2016): 118-141; Jorge Sáiz, Cosme J. Gómez y Ramón López Facal «Narrativas nacionales y competencia histórica entre futuros maestros de Educación Primaria en España», Arbor (en prensa, 2017); Jorge Sáiz e Isabel Barca, «Students narrating their nation. Models of national narratives of Spanish and Portuguese students», London Review of Education (en prensa). 
de las representaciones de historia española que relatan estudiantes y futuros docentes.

\section{NARRATIVA NACIONAL, ENSEÑANZA Y USOS PÚBLICOS DE LA HISTORIA}

Desde el origen de la historia como disciplina escolar, con la génesis de los sistemas educativos liberales, el relato histórico presente en los manuales refleja una representación del pasado que los estados-nación pretenden privilegiar destinada a construir y legitimar la propia identidad nacional. Se trata de uno de los usos públicos de la historia de mayor alcance social, que tiene como protagonista la nación en el pasado. Ello se intensificó con la generalización de sistemas educativos de masas en los estados occidentales a partir de mediados del siglo xx y la consiguiente extensión de la educación secundaria a la mayoría de la población. En este estudio nos aproximarnos a la forma y contenido en que se representa en los manuales la historia de España contemplándola como narrativa nacional.

Este trabajo parte de una hipótesis: la existencia de grandes narrativas maestras de nación, entendidas como representaciones nacionalizadas de la historia de una nación y como construcciones culturales sostenidas por los propios estados-nación y sus comunidades de historiadores profesionales desde la larga duración. Se trataría de grandes relatos que codifican la historia oficial de cada nación, desde unos remotos orígenes hasta la actualidad y que vinculan pasado y presente con un protagonismo continuo de la nación. ${ }^{7}$ Serían, en gran medida, las responsables de fundamentar históricamente los discursos de nación que van apareciendo en el siglo XIX legitimando el discurso social compartido necesario para que las personas construyeran su identidad nacional. Dichas narrativas se originaron en ámbito histórico-académico a lo largo del siglo XIX, reinterpretando episodios y personajes del pasado cuando los estados-nación buscaban legitimar su memoria. Nación es narración en la medida en que la nación se construye, representa y se reproduce narrativamente. ${ }^{8}$ La historiografía de cada estado-nación iría generando sus respectivas

\footnotetext{
${ }^{7}$ Sobre la narrativa nacional véase: Jorge Sáiz, Educación histórica y narrativa nacional, 37-41.

${ }^{8}$ Homi Bhabha, «Introducción: narrar la nación», en Nación y narración. Entre la ilusión de una identidad y las diferencias culturales, comp. Homi Bhabha (Madrid: Siglo, XXI, 2010), 1-11; Stephan Berger, «Narrating the Nation: Historiography and Other Genres», en Narrating the Nation Represen-
} 
narrativas donde plasmarían el progreso de cada nación desde la antigüedad hasta el presente dotándolas de un origen inmemorial y natural que permitía legitimar los estados-nación decimonónicos. ${ }^{9}$ La práctica profesional de la historia, la historiografía académica, nacería a lo largo del siglo XIX precisamente construyendo en forma narrativa ese pasado nacional y haciendo de los historiadores activos agentes de construcción nacional. ${ }^{10}$ Durante el siglo XIX y buena parte del siglo XX, con un cuestionamiento tras los traumas de la Segunda Guerra Mundial, el tema dominante en las diferentes historiografías europeas será una constante: la nación propia. Las narrativas nacionales se constituyen en el canon o formato oficial de las historias de los estados-nación europeos y funcionarán como narrativas maestras próximas y paralelas a las de religión, clase o etnia, con las que en ocasiones entablan estrechos vínculos. ${ }^{11} \mathrm{Di}$ chas narrativas nacionales son claves en los discursos nacionalistas de los estados-nación. Desde el siglo XIX y también hoy en día, influyen en los usos públicos de la historia tanto en ámbito educativo, al tener notable presencia en currículos y manuales de historia escolar, como en ámbito informal, al estar presentes en múltiples textos e imágenes en arte y medios de comunicación de masas (literatura, arquitectura, escultura y pintura, cómic, música, ópera, periodismo, radio, cine, televisión, etcétera); la presencia y popularidad de sus representaciones es notoria en los plurales flujos de comunicación social de la cultura contemporánea. ${ }^{12}$

En el currículo y en los libros de texto de historia escolar, la presencia de narrativas nacionales una nota común todavía hoy en día, como des-

tations in History, Media and Arts, eds. Stephan Berger, Linas Eriksonas y Andrew Mycock (Nueva York-Oxford: Berghahn, 2008), 1-16.

${ }^{9}$ Linda Symcox y Arie Wilschut, «Introduction», en National History Standars. The problem of the canon and the future of teaching History. International review of History education, eds. Symcox y Arie Wilschut (Charlotte: IAP: 2009), 1-11; Etiene Balibar «La forma nación: historia e ideología», en Raza, nación y clase, eds. Immanuel Wallerstein y Etiene Balibar (Madrid: IEPALA, 1991), 135-167.

${ }^{10}$ Stephan Berger y Chris Lorenz, «Introduction», en Nationalizing the Past. Historians as Nations Builders in Modern Europe, eds. Stephan Berger y Chris Lorenz (Londres: Palgrave McMillan: 2010), 1-25.

${ }^{11}$ Stephan Berger y Christoph Conrad, The Past as History. National Identity and Historical Consciousness in Modern Europe (Londres: Palgrave McMillan, 2015), 1-21; Stephan Berger, «Retorn al paradigma nacional? L'escriptura de la història nacional a Alemanya, Itàlia, França i el Regne Unit del 1945 al present», en La persistència de la nació. Estudis sobre nacionalisme, ed. Ferran Archilés (Valencia: PUV, 2015), 101-182.

12 Stephan Berger, Linas Eriksonas y Andrew Mycock (eds.) Narrating the Nation. 
tacan recientes y diferentes estudios. ${ }^{13}$ La historia escolar, como la académica, nació para difundir un relato homogeneizador del pasado colectivo nacional: el fin era construir y reforzar las naciones como «comunidades imaginadas» creando los lazos de identificación colectiva, de identidad nacional, necesarios. ${ }^{14}$ Actualmente la finalidad de la historia escolar sigue más cerca de una perspectiva romántica de construcción de identidades nacionales que de una formación crítica de la ciudadanía. ${ }^{15}$ Las investigaciones señalan la estrecha relación entre los libros de texto de historia escolar y los procesos de nacionalización. Como señala S. Foster ${ }^{16}$ los manuales de historia, reflejo del currículo vigente en cada estado, mantienen al respecto dos rasgos específicos: su carácter claramente nacionalista y el reflejo de una historia oficial en formato narrativo. Se trata de una narrativa nacional o relato histórico del pasado de la nación. En algunos recientes debates sobre el contenido de la historia escolar en sociedades globales y con múltiples identidades, incluso se reivindica explícitamente, por parte de políticos y educadores, el mantenimiento de un «canon» para la historia escolar, término usado para la gran narrativa histórica oficial de cada

${ }^{13}$ Stephan Berger, «De-Nationalizing History and Nationalizing It Differently! Some Reflections on How to Defuse the Negative Potential of National(ist) History Teaching», en History Education and the Construction of National Identities, eds. Mario Carretero, Mikel Asensio y María Rodríguez Moneo (Charlotte CT: IAP, 2012), 33-48; Stuart Foster, «Re-thinking historical textbooks in a globalized world», en History Education and the Construction of National Identities, 49-62; Maria Grever y Siep Stuurman, (eds.), Beyond the Canon: History for the 21st century (London: Palgrave Macmillan, 2007); Robert Guyver (ed.), Teaching History and the Changing Nation State. Transnational and Intranational Perspectives (Londres: Bloomsbury, 2016); Linda Symcox, y Arie Wilschut (eds.), National History Standars. The problem of the canon and the future of teaching History (Charlotte, NC: IAP: 2009); Joke van der Leeuw-Roord (ed.), History changes. Facts and figures about history education in Europe since 1989 (La Haya: EUROCLIO, 2004) y de la misma autora «Two Steps Forward, One Step Back: Shoring Our Stories and Looking for the Common Threads», en Making a Difference: Fifteen years of EUROCLIO, ed. Dean Smart (La Haya: EUROCLIO, 2007), 66-73; Joseph Zajda (ed.), Nation Building and History Education in a Global Culture (Nueva York-Londres: Springer, 2015).

${ }_{14}$ Mario Carretero, Constructing Patriotism. Teaching History and Memories in Global Worlds (Charlotte CT: IAP, 2011); Mario Carretero, Mikel Asensio y María Rodríguez Moneo (eds.), History Education and the Construction of National Identities.

${ }^{15}$ Keith Barton, «A sociocultural perspective on children's understanding of historical change: comparative findings from Northern Ireland \& the United States», American Educational Research Journal, 38, (2001): 881-893; y del mismo autor, «School History as a Resource for Constructing Identities: Implicacions for Research from the United States, Northern Ireland and New Zeland», en History Education and the Construction of National Identities, 93-108; Mario Carretero y Marian Kriger, « ¿Forjar patriotas o educar cosmopolitas? El pasado y el presente de la historia escolar en un mundo global», en Aprender y pensar la historia, comps. Mario Carretero y James Voss (Buenos Aires: Amorrortu, 2004), 71-98; Juan Sisinio Pérez Garzón, «¿Por qué enseñamos Geografía e Historia? ¿Es tarea educativa la construcción de identidades», Historia de la Educación, 27 (2008): 37-55.

16 Stuart Foster, «Re-thinking historical textbooks in a globalized world», 49. 
país donde se seleccionan personajes, eventos, ideas o valores que deben aprenderse en aras a una adecuada nacionalización cultural y política. ${ }^{17}$

Ese peso de la narrativa nacional es común en la mayor parte de las historias escolares, en unos casos de forma más explícita y directa (Estados Unidos, estados latinoamericanos, Japón, Rusia, Holanda) mientras que en otros lo es de manera implícita (Francia, España) o con un enfoque histórico más procedimental, como ocurre el Reino Unido. ${ }^{18}$

Sostenemos la hipótesis de que en España como estado-nación consolidado también existiría una potente narrativa maestra de nación cuya importancia iría más allá de su reflejo en contenidos de historia escolar o en la historiografía académica al constituir el canon tradicional sobre el pasado nacional que nutre el discurso del nacionalismo banal español. ${ }^{19} \mathrm{Su}$ influencia sería notoria en ámbitos escolar y extraescolar, particularmente en productos culturales de masas como series de TV de inspiración histórica. Supondría un referente de larga duración para la construcción de la identidad nacional española.

La narrativa nacional de España fue construyéndose a lo largo del siglo XIX, paralelamente a la consolidación del estado-nación y nacionalismo español, aunque se difundió a gran escala a lo largo del siglo Xx. Dicho relato codificó unos contenidos esencialistas que remontaban la unidad de «España» (con fronteras estables o con unificación jurídico-territorial) o el origen de un colectivo de «españoles» a periodos pre-contemporáneos. ${ }^{20}$ Entre los hitos de dicha narrativa destacan contenidos como los siguientes: la impronta del pasado íbero, la romanización de Hispania como uni-

${ }_{17}$ Siep Stuurman y Maria Grever, «Introduction: Old Canons and New Histories», en Beyond the Canon, 1-18, Peter Lee, «From National Canon to Historical Literacy», en Beyond the Canon, 19-30; Joke van der Leeuw-Roord, «Two Steps Forward, One Step Back».

${ }^{18}$ Keith Barton y Linda Levstik, Teaching History for the Common Good (Nueva York-Londres: Routledge, 2004); Keith Barton, «School History as a Resource for Constructing Identities»; Mario Carretero, Constructing Patriotism; Stuart Foster, «Re-thinking historical textbooks in a globalized world»; Nicole Tutiaux-Guillon, «A Tradicional Frame for Global History: The Narrative of Modernity in French Secondary School», en History Education and the Construction of National Identities, 199124; Joke van der Leeuw-Roord, «Two Steps Forward, One Step Back», y de la misma autora History changes.

${ }^{19}$ Michael Billig, Nacionalismo banal (Madrid: Capitán Swing, 2014), edición original inglesa de 1995.

${ }^{20}$ Ramón López Facal, «Identificación nacional y enseñanza de la historia (1970-2008)» Historia de la Educación, 27 (2008): 171-193; Ramón López Facal y Jorge Sáiz, «Spain: History Education and Nationalism Conflicts», en Teaching History and the Changing Nation State, 201-215. 
ficación política, el reino visigodo como unidad embrionaria de España, la pérdida de la misma con la dominación musulmana, la Reconquista cristiana como largo proceso hacia la unidad de España, su definitivo logro y auge con los Reyes Católicos y su esplendor e inicio de declive con los Austrias. Las dimensiones esencialistas y organicistas de dicha narrativa nacional llegaron a su mayor paroxismo durante la educación histórica nacional-católica del Franquismo, ${ }^{21}$ aunque fueron creadas antes y sobrevivirían después. Durante la Transición democrática esas visiones esencialistas quedaron silenciadas, como una nación ocultada. ${ }^{22}$ Era un proceso paralelo a la desnaturalización del nacionalismo español, asociado al pasado y a la dictadura, y a la emergencia de nacionalismos alternativos (catalán, vasco, etc.), legitimados por su discurso de modernidad, europeísmo y oposición a la misma. Pero ello no implicó que el discurso esencialista fuera sustituido de la memoria colectiva de finales del siglo Xx por otro más cívico e integrador. Paralelamente, la historiografía académica desde los años 70 y 80 revisitaba e impugnaba el grueso de la dimensión organicista de dichos hitos: la Reconquista cristiana, la unidad de los Reyes Católicos o el imperio de los Austrias quedaban contextualizados en una visión comparativa de ámbito europeo más amplia y compleja, desproveyéndoles de la excepcionalidad esencialista española. Con todo, desde los años 90 la narrativa nacional española recobraría protagonismo público de la mano de un neo-nacionalismo español preocupado por difundir un relato ejemplar de la historia, como progreso normalizado hacia la modernidad. En dicho discurso se recuperaron elementos esencialistas, como la antigüedad del estado y la nación española, vinculada a fases tradicionales de unión política (Reyes Católicos, los Austrias), pero también una visión teleológica del siglo xx hacia la democracia.

En definitiva, entre los años 70 y la actualidad, los principales contenidos esencialistas de la narrativa nacional han quedado claramente cuestionados en ámbito historiográfico. Cierto es que un sector de la historiografía española, representado en la Real Academia de la Historia,

\footnotetext{
${ }^{21}$ Rafael Valls, La interpretación de la Historia de España y sus orígenes ideológicos en el bachillerato franquista: 1938-1953 (Valencia: ICE, 1984).

22 Ramón López Facal, «La nación ocultada», en La gestión de la memoria. La historia de España al servicio del poder, Juan Sisinio Pérez Garzón et al. (Barcelona: Crítica, 2000), 111-160.
} 
se mantiene fiel al relato clásico de España. ${ }^{23}$ Cierto es también que perduran determinados términos asociados al relato tradicional, como la aceptación del de «Reconquista» por el medievalismo español. ${ }^{24}$ Pero no podría dudarse que el grueso de la historiografía académica ya no defiende que España nazca como estado y nación con los Reyes Católicos. ${ }^{25}$ No obstante, esas visiones académicas parece que no han llegado todavía a la memoria colectiva sobre la historia nacional. Esos hitos perdurarían en ámbito informal, en usos divulgativos y no historiográficos del pasado histórico, particularmente en medios de comunicación de masas. La impugnación historiográfica de esos hitos (Reconquista, unidad de España con los Reyes Católicos, imperio español) no se habría visto acompañada por su sustitución por un relato más crítico que los llegase a cuestionar. Sostenemos la hipótesis que las representaciones nacionalizadas de un pasado de Reconquista, Reyes Católicos e imperio español sobrevivirían al suponer un valor cultural clave en los discursos político y cultural del nacionalismo español como nacionalismo banal de estado consolidado. De hecho, sobre el nacionalismo español ya contamos con variadas investigaciones sobre los contenidos de sus discursos y su relación con los usos públicos de la historia; ${ }^{26}$ y en algunos trabajos se señala su omni-

${ }^{23}$ Juan Sisinio Pérez Garzón, «El nacionalismo español: los resortes de una hegemonía política y cultural», en Pensar històricament. Ėtica, ensenyament i usos de la historia, ed. Marició Janué (Valencia: PUV, 2009), 123-145.

${ }^{24}$ Antoni Furió, «Las Españas medievales», en Historia de las Españas. Una aproximación crítica, eds. Juan Romero y Antoni Furió (Valencia: Tirant Humanidades, 2015), 77-145; Jorge Sáiz, «La Península Ibérica medieval y las identidades en los actuales libros de texto de historia de $2 .^{\circ}$ de ESO", Íber. Didáctica de las Ciencias Sociales, Geografía e Historia, 70 (2012): 67-77; y del mismo autor «¿Hay sitio para la Edad Media en las enseñanzas primaria y secundaria?», en Nuevos temas, nuevas perspectivas en historia medieval, ed. Ester López (Logroño: IER, Instituto de Estudios Riojanos), 183-214.

${ }^{25}$ Antonio M. Bernal, «Colonias, imperio y estado nacional», en Historia de las Españas, 203-237.

26 José Álvarez Junco, Dioses útiles. Naciones y nacionalismo (Madrid: Galaxia Gutteberg, 2016); José Álvarez Junco (coord.), Las historias de España. Visiones del pasado y construcción de identidad, Historia de España vol. 12, eds. Josep Fontana y Ramón Villares (Madrid: Marcial Pons, 2013); Ferran Archilés e Ismael Saz (eds.), Naciones y estado. La cuestión española (Valencia: PUV, 2014); Ricardo García Cárcel, Las herencias del pasado. Las memorias históricas de España (Madrid: Galaxia Gutenberg, 2013); Jordi Muñoz, La construcción política de la identidad española: ¿del nacionalcatolicismo al patriotismo democrático? (Madrid: CIS, 2012); Pedro Ruiz, «Los usos de la historia en las distintas maneras de concebir España», en Historia de las Españas, 27-75; Ismael Saz y Ferran Archilés (eds.), La nación de los españoles. Discursos y prácticos del nacionalismo español en la España contemporánea (Valencia: PUV, 2012); Carlos Taibo (dir.), Nacionalismo español. Esencias, memorias e instituciones (Madrid: Libros de la Catarata: 2007); y del mismo autor Sobre el nacionalismo español (Madrid: Libros de la Catarata: 2014). 
presencia en ámbitos de socialización cotidiana y entre la historiografía académica. ${ }^{27}$

\section{METODOLOGÍA Y FUENTES PARA ANALIZAR EL DISCURSO DE NACIÓN EN LIBROS DE TEXTO Y EN RELATOS DE ESTUDIANTES}

\section{Analizar el discurso de narrativa nacional en manuales escolares: muestra y modelo conceptual}

Se pretenden examinar los cambios y continuidades de la narrativa nacional española en los libros de texto de historia en secundaria entre los años 70 y la actualidad. Seleccionamos tres hitos claves de la misma: la Reconquista como proceso de expansión cristiana sobre la península ibérica musulmana, la unidad política de los Reyes Católicos y el modelo de estado conformado y finalmente el imperio y hegemonía española de los Austrias. La muestra del estudio son 21 manuales de historia escolar en secundaria entre 1976 y hoy en día, recogidos en el anexo final. Constituyen una muestra probabilística al recoger ejemplares de editoriales de amplia circulación en centros escolares. ${ }^{28}$ Se examinan manuales de historia escolar en secundaria en tres periodos y con diferentes diseños curriculares, a partir de sus ediciones valencianas. En primer lugar, con la Ley General de Educación (LGE), editados entre 1977-90, de la materia Geografía e Historia de España de tercero de Bachillerato Unificado Polivalente (BUP), cinco ejemplares de las editoriales Anaya, Edelvives y Vicens Vives. En segundo lugar, con la Ley Orgánica de Educación (LOE), editados entre 2008-2010, de la materia Ciencias Sociales, Geografía e Historia de segundo de Educación Secundaria Obligatoria (ESO), cinco ejemplares, y de la materia Historia de España, de segundo de Bachillerato otros cinco ejemplares, de las editoriales Anaya, Ecir, Santillana, SM y Vicens Vives. Y finalmente, en tercer lugar, de la actual Ley Orgánica de Mejora de la Calidad Educativa (LOMCE) editados en 2016, seis ejemplares, tres de Geografía e Historia de segundo de ESO y tres de

${ }^{27}$ Ferran Archilés, «Melancólico bucle. Narrativas de la nación fracasada e historiografía española contemporánea», en Estudios sobre nación y nacionalismo en la España contemporánea, eds. Ismael Saz y Ferran Archilés (Zaragoza: Prensas Universitarias de Zaragoza, 2011), 245-330; Álvar Peris, «Nación española y ficción televisiva. Imaginarios, memoria y cotidianidad», en La nación de los españoles, 392-418; Jorge Sáiz, Educación histórica y narrativa nacional, 397-398.

${ }^{28}$ Rafael Valls, Historiografía escolar española. 
Historia de España de segundo de bachillerato, de las editoriales Anaya, Santillana y Vicens Vives.

El objetivo es estudiar en todos ellos desde el observatorio de los contenidos antes señalados el contenido y la forma del discurso de narrativa nacional española.

En primer lugar examinamos el contenido historiográfico del discurso en los tres hitos significativos del relato nacional seleccionados.

Por un lado, juzgamos si se valora de forma crítica el fenómeno de expansión cristiana sobre la península ibérica musulmana, utilizando o no el término "Reconquista», y si al hacerlo se valora o no su viabilidad, informando de la dimensión ideológica que tiene dicho término. De hecho, la expresión «Reconquista» nació a fines del XIX durante la Restauración borbónica dotando de valor patriótico a un término ya existente y creando una construcción historiográfica y política del pasado medieval peninsular ${ }^{29}$ : suponía representar la expansión cristiana sobre los musulmanes, identificados como los «otros», como un lenta unificación territorial y gestación de España, como mito fundacional de la identidad española o de sus identidades regionales. Los medievalistas aceptan hoy en día, excepto una minoría crítica, el término "Reconquista» para caracterizar la expansión política, territorial y militar de los estados feudales cristianos sobre al-Ándalus; no han creado un término alternativo al tradicional, reconocen su naturaleza de justificación ideológica a posteriori y consideran que esa denominación habría quedado desprovista de su originaria carga identitaria. ${ }^{30}$ No obstante dicha dimensión nacional española sobreviviría en discursos del nacionalismo español y en usos divulgativos y no académicos del pasado medieval peninsular ${ }^{31}$. Por lo tanto, la continuidad del término en los manuales podría reforzar y enlazar directamente con esas representaciones nacionalizadas del fenómeno.

\footnotetext{
29 Martín Ríos Saloma, «From the Restoration to the Reconquest: The construction of a national myth (An historiographical review. 16th -19th centuries)», en La España medieval, 28 (2005): 379-414; y del mismo autor, La Reconquista. Una construcción historiográfica (siglos XVI-XIX) (Madrid: Marcial Pons, 2011).

${ }^{30}$ Francisco García Fitz, La Reconquista (Granada: Universidad de Granada: 2010); Martín Ríos Saloma, La Reconquista en la historiografía española contemporánea (Madrid: Sílex, 2013).

31 Antoni Furió, «Las Españas medievales»; Jorge Sáiz, Educación histórica y narrativa nacional y «La Península Ibérica medieval y las identidades».
} 
Por otro lado, estudiamos en los manuales en qué medida se explica el proceso de unidad política peninsular del reinado de los Reyes Católicos, en su dimensión de unidad dinástica y mantenimiento de la diversidad institucional como base de la compleja monarquía hispánica. ${ }^{32} \mathrm{El}$ periodo de los Reyes Católicos es un tema nuclear en el relato histórico de nación española constituyendo uno de las etapas más glorificadas; ${ }^{33}$ a ello responde su condición de reyes de una dinastía local, los Trastámara, frente a los posteriores Austrias o Habsburgo, y su papel unificador fomentando el gobierno conjunto de las dos principales coronas peninsulares (Castilla y Aragón) y completando conquistas político-militares (Granada, Navarra), homogeneidad religiosa (expulsión de los judíos) y expansión atlántica (descubrimiento de América). Dicha valoración positiva nacionalizada también se originó el siglo XIX durante la consolidación del estado-nación español y singularmente reinando otra Isabel, Isabel II, gracias, entre otros, a la obra de Modesto Lafuente. Nació entonces lo que un reciente historiador ha denominado como el «mito de la familia feliz y la unidad nacional», ${ }^{34}$ que llegó a su sublimación y apogeo durante la dictadura franquista. Hoy en día los historiadores reconocen la importancia del reinado pero también señalan la complejidad y fragilidad del modelo político creado por los Reyes Católicos, base de un estado monárquico unido por un gobierno compartido que derivaría en el modelo de monarquía hispánica como monarquía compuesta o federal. ${ }^{35}$ No obstante, consideramos que todavía perduraría en la memoria colectiva española una visión idealizada y nacional de los Reyes Católicos, aquella a la que se acogen discursos del nacionalismo español («España una nación con quinientos años de historia mito de la familia feliz y la unidad nacional»), o a la que remite la popularidad de recientes series de Televisión como «Isabel».

Finalmente, también nos interesa valorar hasta qué punto se explica o no la existencia de un «imperio español» en una vertiente militar y

\footnotetext{
${ }^{32}$ Antonio M. Bernal, Monarquía e imperio, Historia de España vol. 3, eds. Josep Fontana y Ramón Villares (Madrid: Marcial Pons, 2007).

${ }^{33}$ Henry Kamen, Del imperio a la decadencia. Los mitos que forjaron la España moderna (Madrid: Temas de Hoy, 2006), 79-86; obra reeditada en inglés con ligeros cambios como Imagining Spain. Historical myth and national identity (New Haven y Londres: Yale University Press, 2008).

${ }^{34}$ Ricardo García Cárcel, Las herencias del pasado, 505-514.

35 Antonio M. Bernal, Monarquía e imperio, y del mismo autor «Colonias, imperio y estado nacional», en Las Españas medievales, 203-237.
} 
política glorificadora, valorizando un hegemónico papel de «España» como potencia mundial; o si se informa más de la dimensión plural, europea y atlántica de la monarquía hispánica, matizando la naturaleza «española» de ese poder internacional al contextualizar tanto la dimensión y estructura multiterritorial de dicho «imperio» como sus costes sociales. ${ }^{36}$ De hecho la valoración del reinado de los Austrias ha experimentado importantes cambios en los últimos dos siglos. ${ }^{37}$ En el siglo XIX, los historiadores liberales sentaron las bases de una visión negativa, y parte de la leyenda negra, sobre los primeros Austrias, Carlos I y especialmente Felipe II, vinculándolos al absolutismo: ahogaron las libertades (Comuneros) trajeron autoritarismo y ruina financiera. Hubo que esperar al regeneracionismo tras el desastre del 98 y a los años 30-40 del siglo XIX para que naciera el mito del imperio español, revalorizando la figura de Carlos I (Menéndez Pidal) y el modelo imperial hegemónico, asociado a España, una visión que acabó siendo entusiásticamente acogida por la dictadura franquista. Actualmente, los modernistas analizan el modelo político hispánico y sus posesiones coloniales en el contexto de imperios atlánticos europeos y debaten sobre su menor influencia cohesionadora hacia un estado centralizado «español», a diferencia de los procesos inglés y holandés, precisamente por la naturaleza federal y compuesta originaria de la monarquía. ${ }^{38}$ Pero, al igual que ocurre con los anteriores hitos, es indudable la fuerza que tiene la idea de un «imperio español», en el imaginario nacional ${ }^{39}$ y en los discursos del nacionalismo español: buena prueba sería su presencia y popularidad en usos divulgativos de la historia y en productos culturales (novelas, series de Televisión, etc.) donde sobrevive el mito de España como potencia mundial.

En segundo lugar abordamos las formas del discurso de narrativa nacional a través de marcadores textuales e icónicos (cartográficos o figurativos) que se consideran relevantes al respecto.

\footnotetext{
${ }^{36}$ Antonio M. Bernal, «Colonias, imperio y estado nacional»; Henry Kamen, Imagining Spain, 96-125; Ricardo García Cárcel, Las herencias del pasado, 514-538.

37 José Martínez Millán, «La dinastía Habsburgo en la historiografía española de los siglos XIX y XX», Libros de la Corte.es, 7 (2013): 33-58.

${ }^{38}$ Antonio M. Bernal, «Colonias, imperio y estado nacional»; Henry Kamen, Del imperio a la decadencia; John Elliot, Imperios del mundo atlántico. España y Gran Bretaña en América (1492-1830) (Madrid: Taurus, 2006).

${ }^{39}$ Henry Kamen, Imagining Spain, 206-210.
} 
Por una parte, el uso del término «España» para caracterizar bien los reinos cristianos medievales o, sobre todo, el estado gobernado por los Austrias (reino de España) en lugar de «monarquía hispánica», así como la utilización de los adjetivos «españoles» para definir contenidos no políticos, especialmente de naturaleza cultural o artística. Por otro lado, la aparición de cartografía histórica que evidencia la existencia de España como reino unificado, o simplemente la inclusión de España en mapas políticos o culturales o artísticos, referente de clara nacionalización de los contenidos que ya ha sido objeto de estudios previos de manuales de historia. ${ }^{40}$ Finalmente, el recurso en los manuales a imágenes de pintura histórica nacional decimonónica para informar de episodios o personajes clave en el relato nacional, utilizando en manuales de fines del siglo XX o del siglo XXI imágenes del siglo XIX que nacieron como clara representación nacionalizada del pasado medieval o moderno de una España imaginada por pintores al servicio del estado-nación liberal. ${ }^{41}$

\section{Examinar la mediación de la narrativa nacional en relatos de estudiantes y futuros profesores}

Recogemos los resultados de una investigación cualitativa más amplia iniciada en 2013 y todavía en curso, parte de la cual ha visto la forma de tesis doctoral, que se ha ocupado, entre otros aspectos, del estudio de las representaciones históricas del pasado nacional que son capaces de recordar y relatar estudiantes y docentes en formación. ${ }^{42}$ Partimos de la consideración de las narrativas históricas como fuentes y material empírico básico para conocer las formas de representar, organizar y comprender el pasado histórico, una aproximación que ya cuenta con una tradición de estudios. ${ }^{43}$ En los resultados que aquí ofrecemos han participado

\footnotetext{
40 Ramón López Facal, «La nación ocultada».

41 Tomás Pérez Vejo, España imaginada. Historia de la invención de una nación (Madrid: Galaxia Gutenberg, 2015).

42 Remito a los trabajos citados más arriba en la nota 7.

${ }^{43}$ Con investigaciones en Brasil, Portugal, Canadá, Holanda y Cataluña; señalemos, por citar sólo algunos estudios, los siguientes: Isabel Barca y M. ${ }^{a}$ Auxiliadora Schmidt, «La consciencia histórica de los jóvenes brasileños y portugueses y su relación con la creación de identidades nacionales", Educatio Siglo XXI, 31 (1), (2013): 25-46; Stephane Lévesque, Jean-Philippe Croteau y Raphael Gani «Conscience historiques des jeunes francophones d'Ottawa: sentiment d'appartenance franco-ontarienne et récit du passe», Revue du Nouvel-Ontario, 40 (2015): 177-228; Marc Kropman, Carla Van Boxtel y Janest Van Drie, «Small country, great ambitions: Prospective teachers' narratives and
} 
adolescentes y jóvenes de ambos sexos, sobre todo estudiantes de bachillerato y universitarios. ${ }^{44}$ Para ese colectivo se han diseñado tres instrumentos narrativos. En primer lugar, un relato de la expansión cristiana sobre la península ibérica musulmana realizado como síntesis por universitarios futuros maestros. En segundo lugar un escrito sobre la historia de España en el siglo XX para un destinatario igual (otro estudiante u otro futuro docente) completo desconocedor de la misma. En tercer lugar, un escrito de sintesis de la historia de España que recuerdan y/o que consideran objeto de aprendizaje, en el caso de los docentes en formación. En el examen de dichos relatos partimos del concepto de mediación narrativa y de plantilla narrativa esquemática ${ }^{45}$ aplicable a las narrativas maestras nacionales como artefactos culturales que condicionan y median en las representaciones o recuerdos de personas o de grupos sobre episodios del pasado. Nos interesa específicamente identificar qué retrato sustantivo del pasado ofrecen (qué conocen y qué silencian) y, a partir del mismo, establecer el grado de influencia de una narrativa maestra nacional española. Ello lo valoramos desde dos perspectivas. Por un lado determinando la presencia en sus escritos de contenidos sustantivos (hechos, términos, personajes, etc.) propios de dicha narrativa nacional. Por otro lado examinando formas discursivas específicas que revelan identificación con una nación española como comunidad imaginada en el presente y en el pasado, como la modalización discursiva en el uso de la segunda persona del plural (nosotros, nuestro) o la aparición de los términos «España» $\mathrm{y}$ "españoles» como proyección al pasado desde el presente. El uso de la segunda persona del plural en concreto, es muy común en discursos culturales y políticos públicos en medios de comunicación donde aparece como recordatorio cotidiano de identidad nacional compartido desde

knowledge about Dutch history», en Joined-up history: New Directions in History Education Research, eds. Arthur Chapman y Arie Wilschut (Charlotte: IAP, 2015), 57-84; Edda Sant et al. «How do catalan students narrate the history of Catalonia when they finish Primary Education»», McGill Journall of Education, 50 (2/3), (2015): 341-362.

${ }^{44}$ En una exploración inicial participaron 283 universitarios estudiantes del Grado de Educación Primaria de las Universidades de Valencia y Murcia. Posteriormente han intervenido 403 adolescentes y jóvenes valencianos: 220 estudiantes de $10^{\circ}$ y $2 .^{\circ}$ de Bachillerato en su práctica totalidad de centros públicos de Valencia y su área metropolitana; y 183 estudiantes de la Universidad de Valencia, del último curso del Grado de Educación Primaria (112) y del Máster de Profesor de Educación Secundaria de la especialidad de Geografía e Historia (71).

${ }^{45}$ James V. Wertsch, Voices of Collective Remembering (Cambridge: Cambridge University Press: 2002), y del mismo autor "Specific narratives and schematic narrative templates», en Theorizing historical consciousness, ed. Peter Seixas (Toronto: University of Toronto Press, 2004), 49-62. 
un nacionalismo banal, sea de forma directa o indirecta como «deixis patriótica». ${ }^{46}$ En el estudio de las narrativas también hemos profundizado en sus niveles de complejidad organizativa por el conocimiento y uso de competencias de pensamiento histórico (causalidad, tiempo histórico, consciencia histórica, fuente y prueba) que revelan las destrezas para comprender y dotar de significado al pasado relatado. ${ }^{47}$

\section{RESULTADOS: EL CONTRASTE ENTRE LOS LIBROS DE TEXTO Y LOS RELATOS ESCOLARES}

\section{Cambios y continuidades de la narrativa nacional en los libros de texto de historia}

En el estudio de marcadores de narrativa nacional española presentes en los libros de texto de historia se ha decidido analizar globalmente los manuales de la muestra para interrogarnos en qué medida es posible documentar continuidades discursivas, a pesar de corresponder los 31 manuales examinados a tres marcos legales y curriculares diferentes (LGE, LOE y LOMCE). En primer lugar los cinco ejemplares de manuales de la LGE son de la asignatura Geografía e Historia de España, inicialmente también de "países hispánicos», una materia obligatoria del curso 3. ${ }^{\circ}$ del modelo de bachillerato vigente (BUP) como secundaria postobligatoria: en esta materia los contenidos históricos del currículo se alejan del relato nacional heroico y militarista y ya presentan cierta modernización historiográfica correspondiendo los periodos medieval y moderno, respectivamente, a la «peculiarización» y «universalización» de España. En segundo lugar, los libros de texto de la LOE y la LOMCE corresponden tanto a una materia de la secundaria obligatoria (ESO), Ciencias Sociales, Geografía e Historia, en su $2 .^{\circ}$ curso (donde conviven contenidos de historia universal y de España), como a otra materia de Historia de España obligatoria presente al finalizar el bachillerato, en una clara apuesta de refuerzo del relato nacional. En ambos casos (LOE y LOMCE) el diseño curricular de contenidos mantiene unos mismos ítems característicos

\footnotetext{
46 Michael Billig, Nacionalismo banal, 159-213.

47 Sobre los criterios teóricos y metodológicos de examen de las narrativas, véase Jorge Sáiz, Educación histórica y narrativa nacional, 71-92, y Jorge Sáiz y Cosme J. Gómez, «Investigar el pensamiento histórico y narrativo en la formación del profesorado: fundamentos teóricos y metodológicos", Revista Electrónica Interuniversitaria de Formación del Profesorado, 19 (1), (2016): 175-190.
} 
(Al-Ándalus, Reconquista-Repoblación, Reyes Católicos, Monarquía de los Austrias) que los manuales reproducen con fidelidad. En cierta medida, por tanto, se apreciaría cierta continuidad en los enunciados curriculares primando lo político y dejando un menor margen a los contenidos socio-económicos y culturales. Una continuidad que también puede constatarse en la forma y contenido discursivo de los manuales como se aprecia en la siguiente Tabla 1 donde se ha indicado la presencia de dichos marcadores en la muestra de libros de texto de historia de los tres marcos curriculares.

Tabla 1. Marcadores de narrativa nacional española en manuales escolares de historia (1976-2016)

\begin{tabular}{|c|c|c|c|c|c|c|}
\hline $\begin{array}{c}\text { Ley, años } \\
\text { edición, curso, } \\
\text { n. }{ }^{\circ} \text { ejemplares } \\
\text { analizados }\end{array}$ & $\begin{array}{c}\text { Reconquista } \\
\text { como } \\
\text { proceso: } \\
\text { n. }{ }^{\circ} \text { sobre } \\
\text { total }\end{array}$ & $\begin{array}{c}\text { Reyes } \\
\text { Católicos } \\
\text { unidad } \\
\text { política y } \\
\text { explicación: } \\
\text { n. }{ }^{\circ} \text { sobre } \\
\text { total }\end{array}$ & $\begin{array}{c}\text { Imperio } \\
\text { español y } \\
\text { explicación: } \\
\text { n. }{ }^{\circ} \text { sobre } \\
\text { total }\end{array}$ & $\begin{array}{c}\text { Referencia } \\
\text { textual a } \\
\text { «España»: } \\
\text { n. } .^{0} \text { sobre } \\
\text { total }\end{array}$ & $\begin{array}{c}\text { Referencia } \\
\text { cartográfica, } \\
\text { mapa de } \\
\text { «España»: } \\
\text { n. }{ }^{\circ} \text { sobre } \\
\text { total }\end{array}$ & $\begin{array}{c}\text { Referencia } \\
\text { iconográfica, } \\
\text { pintura } \\
\text { nacional del } \\
\text { siglo XIX: } \\
\text { n. }^{\circ} \text { sobre } \\
\text { total }\end{array}$ \\
\hline $\begin{array}{l}\text { LGE, 1977-90, } \\
3 .^{\circ} \text { BUP, } 5\end{array}$ & $5 / 5$ & $5 / 5$ & $1 / 5$ & $4 / 5$ & $1 / 5$ & $2 / 5$ \\
\hline $\begin{array}{l}\text { LOE, 2008-10, } \\
2 .^{\circ} \mathrm{ESO}, 5\end{array}$ & $5 / 5$ & $5 / 5$ & $3 / 5$ & $5 / 5$ & $4 / 5$ & $5 / 5$ \\
\hline $\begin{array}{l}\text { LOE, } 2009,2 .^{\circ} \\
\text { Bto. } 5\end{array}$ & $4 / 5$ & $5 / 5$ & $3 / 5$ & $5 / 5$ & $3 / 5$ & $2 / 5$ \\
\hline $\begin{array}{l}\text { LOMCE, 2016, } \\
2 .^{\circ} \text { ESO (3) y } \\
2 .^{\circ} \text { Bto (3), } 6\end{array}$ & $4 / 6$ & $6 / 6$ & $2 / 6$ & $4 / 6$ & $4 / 6$ & $6 / 6$ \\
\hline Total: 21 & $18 / 21$ & $20 / 21$ & $9 / 21$ & $18 / 21$ & $12 / 21$ & $14 / 21$ \\
\hline
\end{tabular}

Fuente: Elaboración propia.

Comencemos con el examen de los contenidos historiográficos del discurso de los manuales. En este ámbito, como se ve en la Tabla 1, de los tres procesos históricos seleccionados, en dos de ellos (Reconquista y unidad de los Reyes Católicos) los manuales incluyen los contenidos esperados.

En primer lugar, la mayor parte de los manuales recurren sin matiz alguno al término "Reconquista» para caracterizar la expansión de los estados feudales cristianos. En este aspecto reproducen la aceptación 
normalizada del término que la propia historiografía medieval española realiza ya que, como se indicó, no se ha acuñado una expresión alternativa. Pero si no se matiza o explica adecuadamente el proceso, el uso de la expresión "Reconquista» no permite eludir la evidente e indirecta carga nacionalizadora española que conlleva el mantenimiento de dicha denominación tradicional. Sólo tres ejemplares de la editorial Vicens Vives (para 2..$^{\circ}$ de ESO de 2009 y 2016, y para 2. ${ }^{\circ}$ de bachillerato de 2016) eluden dicho término, hablando sólo de conquista o expansión cristiana; y únicamente dos volúmenes (los de 2. ${ }^{\circ}$ ESO de Santillana, 2008 y de $2 .^{\circ}$ Bachillerato de SM, 2009), introducen matices críticos a la expresión «Reconquista». En concreto plantean, en forma de actividad de razonamiento o como debate, lo apropiado del uso de la palabra «Reconquista» por su dimensión ideológica y propagandística. A nuestro juicio, un uso crítico de dicha expresión hubiera implicado que el grueso de los manuales permitiera matizar o profundizar en las dimensiones del término o, incluso, que se hubiese prescindido del mismo. Al no hacerse ello y al dejarse al uso o explicación de los docentes la adecuación de la denominación "Reconquista», no parece probable que el contenido de los manuales aporte materiales para impugnar o cuestionar las mayoritarias y nacionalizadas representaciones del fenómeno que sobreviven en los usos populares y no académicos del pasado histórico medieval, particularmente en fiestas populares como las de Moros y Cristianos o en festividades como el 9 de octubre valenciano que vinculan las conquistas cristianas como orígenes inmediatos de las identidades española y valenciana.

Por otra parte, todos los manuales dedican unas líneas a explicar la naturaleza de la unidad política lograda por el matrimonio de los Reyes Católicos, Isabel de Castilla y Fernando de Aragón, entre las coronas de Castilla y Aragón, insistiendo directamente en su carácter de gobierno conjunto, «unión personal» o «unión dinástica». Algunos manuales, como los de la editorial Vicens Vives - y ya desde el clásico manual de 1977 «Ibérica»—, insisten en lo inapropiado de hablar de «reyes de España» para los Reyes Católicos, explicando claramente la naturaleza federal de la unión que nace con ellos. Esta cuestión, la de la dimensión federal o de unión de reinos y principados diferenciados que supone la monarquía hispánica, es señalada y comentada por todos y cada uno de los manuales analizados. Incluso uno de ellos (2. ${ }^{\circ}$ de Bachillerato, 
SM, 2009) dedica una página de actividad al debate siguiente: "¿existía España como estado con los Reyes Católicos?». Dada la transcendencia del fenómeno se trata, sin lugar a dudas, de una relevante actividad que permite plantear desde el principio y con una correcta adecuación historiográfica el modelo de monarquía compuesta que supone la monarquía hispánica de los Austrias.

Esta unanimidad no se localiza en el contenido del «imperio español» ya que menos de la mitad de los manuales examinados, como se ve en la Tabla 1, recurren a tal expresión. En su lugar se utilizan las más apropiadas de «imperio hispánico» o «hegemonía hispánica». Vemos, por tanto, una menor referencia explícita y textual a la dimensión militar y política de una hegemonía o potencia hispánica. Con todo, en los manuales más recientes examinados para $2 .^{\circ} \mathrm{ESO}$, editados en 2016 con la LOMCE, esta menor referencia textual se compensa con el recurso a dibujos de recreación histórica específicos que abordan las formas organizativas y los emblemas de la infantería de los Tercios, en una clara representación del poder militar de los Austrias. Por su parte, el tema de los costes sociales del imperio y hegemonía hispánicos, singularmente en el continente americano, tratando el impacto humano de la conquista y colonización, sí que aparece abordado por la práctica totalidad de manuales de $2 .^{\circ}$ de ESO.

Esta escasa presencia en el texto académico de los manuales del contenido tradicional y esencialista del relato nacional, que hemos visto impugnada por su adecuación historiográfica, contrasta con los elementos formales textuales e icónicos del discurso. En esa dimensión formal del discurso sí que documentamos marcadores de continuidad con la narrativa nacional o relato nacionalizado del pasado. Son formas discursivas, textuales e icónicas, que entran en clara contradicción con el contenido académico de los manuales.

Vemos así, por un lado, cómo la mayoría de los manuales emplean el término «España» o el adjetivo "español» para contenidos del periodo medieval o moderno (Tabla 1, 18/21), aunque con diferentes intensidades y dimensiones. Todos los manuales de $3 .^{\circ}$ de BUP, excepto el de la editorial catalana Vicens Vives, recurren a ello. Y en todos los manuales LOE de $2 .^{\circ}$ ESO y $2 .^{\circ}$ de Bachillerato - excepto el de SM- se hace patente el empleo mayoritario de ambos términos. Unas expresiones que se con- 
centran claramente en dos ámbitos. En primer lugar, están localizadas ubicuamente en contenidos de naturaleza cultural (arte y literatura), más en el periodo de la edad moderna que en el medieval. En segundo lugar, también lo documentemos con expresiones que remiten a una dimensión territorial o cronológica para identificar periodos o reinados: es el caso de fórmulas como «España medieval», «España de los Austrias», «España imperial», «España de Carlos I», etc. Ese uso discursivo formal del imaginario de «España» no supone más que la asunción indirecta de la normalidad con que los discursos del nacionalismo banal representan el presente y el pasado como un orden de países y estados-nación. Con todo, contrasta con el contenido del texto académico del manual cuando ha explicado el modelo político de la monarquía hispánica.

Por otro lado, es muy significativo el hecho de que la cartografía histórica de los manuales sí represente «España» como estado entre los siglos XVI y XVII, en la dinastía de los Austrias, a pesar de que en el contenido textual se respete la adecuación historiográfica de la inexistencia de un reino unificado de España anterior al siglo XVIII. No es una casualidad que en los manuales más antiguos de $3 .^{\circ}$ de BUP no aparezca un mapa de «España» ya que se corresponde con la propia escasa presencia de cartografía histórica en esos primeros manuales: de hecho sólo figura en el ejemplar de Anaya de 1987 y como «corona española» para el siglo XVI. Ahora bien en todos los manuales de $2 .^{\circ}$ ESO LOE (2008-2010), vemos en los mapas un «reino de España» para los siglos XVI y XVII, siendo las excepciones un ejemplar de Vicens Vives que identifica "España» sólo en mapas de contenidos religiosos o artísticos, y otro de SM que directamente no la cartografía. Esa presencia de España como reino de los siglos XVI y XVII desciende en los mapas de manuales de $2 .^{\circ}$ de Bachillerato LOE, al representarse "España» sólo en posesiones o imperio de Carlos I para los manuales de Ecir y Santillana. Significativamente en el único ejemplar LOE (SM, 2. ${ }^{\circ}$ Bachillerato) que no aparecía textualmente «España», lo hace en cartografía histórica, en un mapa de la Guerra de los Treinta Años. Finalmente, hay que destacar que el grueso de los manuales LOMCE de 2016 (excepto los de 2. ${ }^{\circ}$ de Bachillerato de Vicens Vives y Anaya), cartografían «España» como reino en los siglos XVI y XVII o en mapas de la Reforma y Contrarreforma religiosa. Sorprende incluso que en manuales de 2..$^{\circ}$ ESO de Anaya y Santillana la existencia de España como reino se incluya incluso ya a fines del Xv con los Reyes Católicos, 
entrando en evidente contradicción con el contenido de mera «unidad dinástica».

Finalmente, también podemos documentar la presencia de imágenes de pintura histórica del XIX para ilustrar contenidos históricos nacionales de época medieval y moderna. Este recurso es relativamente escaso en manuales de $3 .^{\circ}$ de BUP, donde el recurso a imágenes figurativas era menor, y también para los libros de $2 .^{\circ}$ de Bachillerato LOE. En estos casos se recurre a dos imágenes clásicas del reinado de los Reyes Católicos y del primer Habsburgo, identificadas en su autor: «La Rendición de Granada» de Francisco Pradilla, cuadro pintado en 1882, y «Los Comuneros Bravo, Padilla y Maldonado en el patíbulo», obra de Antonio Gisbert realizada en 1860. La importancia, datación y origen de las mismas han sido destacadas en el estudio de Pérez Vejo. ${ }^{48}$ En cambio, en todos los manuales de $2 .^{\circ}$ ESO de LOE (2008-2010), así como en todos los de LOMCE de 2016, tanto de 2. ${ }^{\circ}$ de ESO como de $2 .^{\circ}$ de Bachillerato, es generalizado el recurso a la pintura histórica del XIX. En dichos ejemplares, junto las obras ya señaladas, aparecen otras relevantes. En primer lugar, en los libros de 2. ${ }^{\circ}$ de ESO de 2008-2010 constan obras para el tema de la conquista de Granada («Salida de los moros de Granada» óleo sin identificar del siglo XIX) y para el descubrimiento de América con la popular pintura del «Primer desembarco de Cristóbal Colón» realizado por Dióscoro Teófilo Puebla en 1862. En segundo lugar vemos una ampliación del repertorio iconográfico en los manuales de 2016, especialmente los de Santillana, que cubren otros episodios del reinado de los Reyes Católicos (Guerras en Nápoles del Gran Capitán), de Carlos I (Germanías y Comuneros) y de Felipe II (sucesos de Antonio Pérez), o de Felipe IV (guerras con Francia): se trata, para 2..$^{\circ}$ ESO de Santillana, de las obras «La liberación de Antonio Pérez de Zaragoza» de Manuel Ferrán de 1864 $\mathrm{y}$ «El cardenal Adriano de Utrecht recibiendo a los agermanados» de José Benlliure de 1872; para 2. ${ }^{\circ}$ de Bachillerato de Santillana, de «El Gran Capitán recorriendo el campo en Ceriñola» de Federico de Madrazo de 1835 y «La Batalla de Villalar» de Manuel Piccolo López de 1881; y para 2. ${ }^{\circ}$ de Bachillerato de Vicens Vives, de «Doña María Pacheco de Padilla después de Villalar» de Vicente Borrás de 1881, y «La batalla de Rocroi» de Víctor Morelli Sánchez-Gil de 1912.

\footnotetext{
${ }^{48}$ Tomás Pérez Vejo, España imaginada.
} 


\section{Pervivencia de representaciones esencialistas y nacionalizadas en relatos de estudiantes}

El examen de los relatos de los estudiantes revela una educación histórica claramente descompensada. Nos centraremos en ofrecer perfiles generales sobre los resultados evidenciados en estudiantes que finalizan bachillerato y en universitarios en formación de maestros de Educación Primaria. La mayoría de narrativas históricas analizadas muestran que los adolescentes y jóvenes son capaces de aportar contenidos sustantivos representativos, aunque fragmentarios, del relato del estado-nación, con especial relevancia de los hitos que protagonizan este estudio (Reconquista, Reyes Católicos, imperio). Ahora bien ello lo hacen sin competencias históricas para dotar de significado a dichos contenidos (causalidad o explicación multicausal, orientación temporal y uso flexible del tiempo histórico); es decir, sin mostrar niveles de complejidad expositiva que revelen una comprensión histórica adecuada de los fenómenos. El grueso de adolescentes y jóvenes muestra en sus escritos que ni conoce ni usa competencias históricas, al no haberlas aprendido en sus clases de historia donde se ha limitado a memorizar y reproducir textos académicos. Precisamente por ello carecen de capacidad analítica y crítica frente al relato tradicional. Conocen poco y en un nivel descriptivo y memorístico. De hecho, dejando al margen la existencia de relatos nulos o fragmentarios, algo más de la mitad del total de textos ofrecen unos mínimos contenidos sustantivos. En su mayoría son capaces de identificar etapas características de la historia de España. Pero la dimensión de contenidos ofrecidos presenta un nivel puramente descriptivo y lineal que privilegia el cambio político: identifican etapas y periodos sin demostrar comprender su significado histórico más allá del encadenamiento de fases políticas.

En el conjunto de textos destacan dos periodos y personajes clave: Franco y los Reyes Católicos. Dejando al conocimiento de la contemporaneidad el recuerdo de Franco, es más que relevante la importancia que tiene el reinado de los Reyes Católicos en las narrativas históricas de estudiantes ya que aparece en casi todos los escritos. Ahora bien, la práctica totalidad de textos carece de un conocimiento suficiente sobre el modelo de estado y gobierno de los Reyes Católicos, limitándose bien a reproducir una vaga idea de unidad política en clave de origen de la 
actual unidad española, bien a realizar una valoración positiva y mitificadora de su reinado («Reconquista» de Granada descubrimiento de América, etc.)

Esta representación nacionalizada del reinado de los Reyes Católicos y del final de la Reconquista podemos evidenciarla claramente en estos seis fragmentos de relatos, tanto de estudiantes de bachillerato como de universitarios futuros maestros, cuyos contenidos son muy significativos:

En el principio en la península ibérica estaban los visigodos entre otros. Luego fue conquistada por los musulmanes los cuales estuvieron aquí durante mucho tiempo [...] después pasó a ser conquistada por los Reyes Católicos los cuales ya cambiaron y unificaron España (mujer, 18 años, $1 .^{\circ}$ de bachillerato).

España, país de donde soy, ha sufrido muchos cambios políticos, sociales y culturales a lo largo de su historia. Pasó de ser visigoda a musulmana en el siglo VIII y finalmente reconquistada por los cristianos en el siglo Xv. Tuvo éxitos, como el descubrimiento de América e incluso llegó a ser primera potencia mundial. También tuvo fracasos como las pérdidas de territorios como Gibraltar, por ejemplo (hombre, $2 .^{\circ}$ de bachillerato, 19 años).

Después de varios siglos España fue conquistada por los árabes [...] Pero España fue poco a poco reconquistada por un grupo de cristianos refugiados en el norte. Ese proceso fue creando diferentes reinos españoles: Castilla, Aragón, Navarra [...] España tuvo una época de auge con ocasión de los Reyes Católicos, Isabel de Castilla y Fernando de Aragón que unificaron sus reinos, conquistaron el último reino musulmán, el de Granada, y financiaron el descubrimiento y conquista de América. Fue una época cumbre para España (mujer, 2. ${ }^{\circ}$ de bachillerato 17 años).

La Reconquista fue un largo proceso que duró casi seis siglos en el que poco a poco las tropas españolas fueron avanzando de norte hacia abajo, conquistando los territorios y expulsando a los musulmanes [...] Liderados por Jaime I el año 1238 las tropas españolas llegaron a Valencia y el 9 de octubre conquistaron el territorio valenciano (mujer, $4 .^{\circ}$ Grado de Educación Primaria, 21 años). 
Los cristianos comenzaron a reconquistar los territorios de norte a sur de la península e hicimos que los musulmanes se fueran retirando [...] Con la llegada de los Reyes Católicos asistimos a la unificación territorial y al reforzamiento de la Corona y entonces los Reyes Católicos en 1492 acabaron la Reconquista de España (mujer, 4. ${ }^{\circ}$ Grado de Educación Primaria, 21 años).

Como conclusión, lo que finalmente creó la España que actualmente conocemos fue la unión de la reina Isabel de Castilla y Fernando de Aragón, que hizo posible la unión de los territorios y la conquista final de la península ibérica por parte de los cristianos (mujer, $4 .^{\circ}$ Grado de Educación Primaria, 20 años).

En este perfil de relatos, junto al recurso a hitos del relato de nación tradicional, también destaca la modalización discursiva basada en la primera persona del plural así como referencias a «España» y a «españoles» para periodos previos a la contemporaneidad, en ocasiones con valoraciones positivas y/o con dimensiones territoriales o nacionales. Ambos rasgos son marcadores evidentes de una representación nacionalizada del pasado histórico. Es en estos casos donde se documenta más claramente la mediación de la narrativa nacional española y el eje «reconquista-unidad-imperio» como hilo argumental. Así lo vemos en estos tres fragmentos de relatos de estudiantes:

De España historia concreta, solo recuerdo la Reconquista y descubrimiento de América. Colón descubre América en 1492 y la conquista. La Reconquista fue cuando los musulmanes conquistaron la gran parte de España, el norte de España que fue el colonizado, lo reconquistaron. Sé que Castilla y Aragón fueron importantes, pero no recuerdo nada. Y recuerdo uno de los nombres a los que se le puso a España, no un nombre creo, sino una forma de identificar su antiguo poder: España, el país que nunca se pone el sol (mujer, 18 años, $1^{\circ}{ }^{\circ}$ de bachillerato).

En 1492 España, con la expedición de Cristóbal Colón, descubrió las américas. Tras la conquista de éstas, a manos de hombres como por ejemplo Pizarro, España se transformó en el imperio más grande del mundo. Tras una continuada e interminable lista de fracasos bélicos, políticos y sociales, España perdió todas sus colonias y a sus armadas (alumno, 17 años. 1. ${ }^{\circ}$ de bachillerato). 
El auge español tuvo lugar poco antes de la Edad Media y después con los Reyes Católicos Isabel y Fernando en el mando, que hicieron numerosas mejoras y favorecieron la actitud de los colonos hacia la conquista del nuevo mundo. Los Reyes Católicos consiguieron expulsar definitivamente a los moros de Granada [...] Además, a nivel militar, España se organizaba en tercios, los tercios españoles eran fuerza militar comparable con las falanges griegas, que lograron numerosas victorias. Con la riqueza traída de América, el poder a nivel europeo y el alto nivel social, España era un eje en el mundo (alumno, 18 años, $1 .^{\circ}$ bachillerato).

Vemos, por tanto, que un colectivo de estudiantes de secundaria y de futuros docentes de Primaria, en sus relatos de síntesis de historia de España no sólo recurre a hitos propios de la narrativa nacional tradicional sino que también comparte la normalidad discursiva del nacionalismo banal y, por tanto, ni comprende ni se ha planteado la historicidad de la construcción contemporánea de las naciones y el nacionalismo. ${ }^{49}$ Viven en el sentido común cotidiano de las temporalidades nacionales ${ }^{50}$ y comparten el peso hegemónico del pensamiento nacionalista que les dota de "seguridad ontológica», ${ }^{51}$ y todo ello lo expresan en sus relatos escolares sobre el pasado nacional.

El responsable de la presencia de estas narrativas de adolescentes y jóvenes que refieren de forma tan relevante la Reconquista, los Reyes Católicos o el imperio español no parece que sea el texto académico de los manuales escolares, que hemos visto que ha impugnado la representación esencialista nacionalizada del pasado, al menos en el discurso. Hemos de pensar en otras fuentes de conocimiento histórico paralelas a la escolar y de mayor fuerza e impacto. Se trata de los usos informales de la historia, como los medios de comunicación, que sin lugar a dudas también influirían en los conocimientos de los adolescentes y jóvenes. Así lo reconocen ellos mismos, como una estudiante de $1 .^{\circ}$ de bachillerato quien al relatar qué sabe de historia de España reconoce recordar

\footnotetext{
49 Ferran Archilés, «L'estudi de la nació i el nacionalisme», en La persistencia de la nació, 9-41.

50 Tim Edensor, «Reconsiderant les temporalitats nacionals», en La persistència de la nació, 241-276.

51 Michael Skey, National Belonging and Everyday Life. The Significance of Nationhood in an Uncertain World (Basingstoke: Palgrave Macmillan, 2011).
} 
más de recientes series, televisivas o de internet, que de la historia escolar aprendida:

En mis cursos anteriores no di mucho historia de España, dábamos cosas en general, y al final de curso, si llegaba el tema, lo dábamos, pero poco sé de la historia de España, se nombres de cosas que pasaron pero no el hecho en sí. Sé lo de la guerra civil, el descubrimiento de américa, la reconquista de la península, también se pequeñas cosas que vi en una serie de internet, que España tuvo en su poder la parte del sur de Italia, sé que tuvo alguna cosa en Austria, guerras con Inglaterra (que ganamos una batalla que los ingleses no reconocen) [...] Me molesta mucho el hecho de no saber la historia de España. Series como Isabel, Carlos, y el Ministerio del Tiempo están bien [...]. La pena es que solo vi el Ministerio del Tiempo (alumna, 18 años, $1 .^{\circ}$ de bachillerato).

\section{CONCLUSIONES: PERVIVENCIAS DE LA NARRATIVA NACIONAL Y DEBILIDADES DE LA EDUCACIÓN HISTÓRICA}

¿Ha cambiado la representación escolar del pasado histórico de España a lo largo los últimos cuarenta años, tal y como reflejan los libros de texto de historia en educación secundaria y los relatos de estudiantes? Podríamos responder afirmativamente si pensamos que en ese periodo en España finalizó un estado dictatorial que monopolizaba el discurso nacional y se consolidó un estado democrático. Pero las dudas emergen si consideramos la hipótesis de la existencia una narrativa maestra nacional española, como construcción cultural, un relato de nación tradicional y esencialista, nacido a fines del siglo XIX y difundido en el siglo XX y que constituiría un elemento esencial del discurso histórico del nacionalismo español. Dicho relato quedó oculto desde la Transición democrática al tiempo que la historiografía académica impugnaba sus principales hitos (Reconquista, unidad de España con los Reyes Católicos, imperio español). Pero ¿ha desparecido de la historia escolar desde fines de los 70 entre la LGE y la actual LOMCE?

Este estudio muestra que el contenido de la historia escolar ha experimentado notables cambios, entre ellos la adecuación historiográfica desproveyendo a los textos académicos escolares de elementos esencia- 
listas. Lo hemos comprobado examinando el discurso histórico nacional en libros de texto entre 1976 y 2016 desde un análisis crítico y desde la perspectiva socio-cultural. Se ha evidenciado hasta qué punto habría cambiado la representación narrativa nacionalizada de España heredada de la historia escolar franquista. El análisis en manuales escolares de marcadores de contenido y forma del discurso, muestra elementos de cambio y de continuidad en la narrativa nacional. El cambio más relevante es el tratamiento histórico de los hitos analizados. Para la expansión cristiana sobre la península ibérica musulmana si bien se mantiene el término "Reconquista», como hace el medievalismo académico, algunos manuales introducen matices críticos al mismo. Para el periodo de los Reyes Católicos y la monarquía de los Austrias han desaparecido por completo las dimensiones esencialistas ya que los manuales incorporan la dimensión política federal y descentralizada del modelo de estado y no exhiben elementos glorificadores de un imperio español. Con todo, a pesar de estos cambios, se mantendría el hilo del discurso manteniendo la trilogía de "reconquista-unidad-imperio», un elemento nuclear en la representación nacionalizada del pasado español.

Pero observamos otros signos de continuidad en la dimensión formal del discurso que entroncan con la narrativa nacional. Se trata de referencias genéricas a la existencia de España en la Edad Moderna, sobre todo en contenidos artístico-culturales; cartografía histórica que individualiza un «reino de España» para los siglos XVI y XVII; y finalmente el recurso a ilustraciones de pintura histórica del XIX que suponen la reutilización en contexto escolar de imágenes que nacieron y mantienen una función nacionalizadora. En manuales actuales de LOMCE de editoriales de gran difusión, como Santillana y Anaya —no así con Vicens Vives-, se ha podido evidenciar igualmente cómo se intensificarían dichos contenidos formales discursivos de la narrativa nacional.

Como vemos, los elementos de continuidad formal del discurso de narrativa nacional española en manuales de historia escolar entran en contradicción con el contenido historiográfico presente, que en gran medida está actualizado.

El contraste es todavía mayor si observamos cómo narran la historia de España estudiantes que finalizan educación secundaria y algunos futuros docentes. El grueso de adolescentes y jóvenes reproducirían en 
sus narrativas los hitos de la narrativa nacional desde una visión de relato tradicional: la Reconquista y el reinado de los Reyes Católicos como orígenes de la identidad española y unidad de España o la idea de España como potencia imperial son representados en textos de estudiantes y universitarios, en algunos casos con marcadores discursivos de identificación nacional. No manifiestan pensar históricamente la historia y la identidad nacional propias. Se ha podido evidenciar en otros estudios ${ }^{52}$ que sólo son capaces de comprender la construcción histórica contemporánea de las naciones y pueden impugnar las representaciones esencialistas de la historia nacional, una parte de los futuros docentes de historia en Educación Secundaria, quienes han recibido una formación histórica disciplinar. No ocurre igual con la gran mayoría de estudiantes y futuros docentes de Educación Primaria quienes mantienen estas visiones de la narrativa nacional.

Las contradicciones entre el contenido académico de los manuales y las representaciones de estudiantes pensamos que estarían relacionadas con las pervivencias en el imaginario popular de la narrativa nacional española. De hecho, aunque la historiografía rebatiera el discurso esencialista, esta dimensión del relato nacional de España no se sustituyó a nivel popular por otro relato alternativo más crítico. El tema del origen y construcción históricos de la nación española, como el propio nacionalismo español, simplemente se silenciaron e incluso tardaron en cuajar como campo de investigación académica. Por lo tanto, no es de extrañar que las representaciones nacionalizadas de dicho relato sobrevivieran en la memoria colectiva a través de usos culturales y divulgativos de la historia, especialmente en medios de comunicación de masas, algo patente todavía hoy en día en recientes series de Televisión de contenido histórico («Isabel», «Carlos», «El Ministerio del Tiempo»).

Probablemente haya que pensar que las visiones tradicionales sobre la Reconquista, los Reyes Católicos o el imperio español sigan siendo hoy en día anclajes del discurso histórico del nacionalismo español. Un nacionalismo español cuyo tránsito desde el nacional-catolicismo al nacionalismo democrático no se vio acompañado por el reemplazo en el imaginario colectivo de esas visiones esencialistas del pasado. Dichas 52 Jorge Sáiz y Ramón López Facal, «Narrativas nacionales históricas de estudiantes y profesorado
en formación». 
visiones, propias de los discursos de cualquier nacionalismo banal de estado consolidado, incluso podríamos considerarlas más notorias en el caso del nacionalismo español dada su reactivación en los años 90 y su continua competencia con nacionalismos alternativos.

Pero junto a los usos informales o divulgativos del pasado histórico nacional, otro factor clave para comprender la pervivencia de la narrativa nacional en los relatos de estudiantes y futuros docentes, hay que encontrarlo en la pobre educación histórica existente en la educación básica. La historia escolar, desde Primaria a Secundaria, todavía se basa en rutinas de memorización de contenidos académicos sin aprender competencias para dotarlos de significado, como demuestran investigaciones recientes basadas en exámenes, narrativas de estudiantes y libros de texto. ${ }^{53}$ Ello explicaría la notoria presencia de esas visiones simplistas y esencialistas del pasado histórico nacional entre estudiantes, pero también entre docentes en formación, quienes serían incapaces de cuestionar críticamente el relato tradicional de nación y comprender la contemporaneidad e historicidad de la construcción de naciones e identidades nacionales. La historia escolar no fomenta una introducción gradual a competencias de pensamiento histórico ya que las prácticas docentes siguen ancladas en la memorización de síntesis de contenidos factuales. De esta forma el alumnado acaba aprendiendo y recordando únicamente una secuencia lineal de etapas donde incluye personajes, hechos, etc. Aquí encuentran fácil acomodo los difundidos hitos de la narrativa nacional presentes en usos extraescolares de la historia.

\footnotetext{
${ }^{53}$ Cosme J. Gómez y Pedro Miralles, «¿Pensar históricamente o memorizar el pasado? La evaluación de los contenidos históricos en la educación obligatoria en España», Revista de Estudios Sociales, 52 (2015): 52-48; Cosme J. Gómez, Raimundo Rodríguez y Pedro Miralles, «La enseñanza de la Historia en Educación Primaria y la construcción de una narrativa nacional. Un estudio sobre exámenes y libros de texto en España», Perfiles Educativos, XXXVII (150), (2015): 20-38: Jorge Sáiz, «Alfabetización histórica y competencias básicas»; Jorge Sáiz y Carlos Fuster, «Memorizar historia sin aprender pensamiento histórico. Las PAU de Historia de España», Investigación en la escuela, 84 (2014): 46-57; Jorge Sáiz y Ramón López Facal, «Competencias y narrativas históricas».
} 


\section{ANEXO. Libros de texto de historia analizados (1976-2016)}

\section{Libros analizados de $3 .^{\circ}$ de BUP-LGE (1976-1990)}

Anaya, 1977: Valdeón, J., González, I., Mañero, M., Sánchez, D. J. (1976). Geografía e historia de España y de los países hispánicos, Madrid: Anaya.

- 1988: Prats, J., Castellón, J. E., García, M. ${ }^{a}$ C., Loste, M. ${ }^{a}$ A., Izuzquiza, I., Fernández, R. (1988). Geografía e Historia de España, Madrid: Anaya.

Edelvives, 1977: Gutiérrez, J., Fatas, C., Borderías, A. (1977). Geografía e historia de España, Zaragoza: Edelvives.

- 1990: Bosch, D., González, M. ${ }^{a}$ I., Labrada, M. ${ }^{a}$ A., Mataix, M. ${ }^{a}$ C. (1990). Geografía e Historia de España Bup 3, Zaragoza: Edelvives.

Vicens-Vives, 1977: Balanzá, M., Benejam, P., Llorens, M., Ortega, R., Roig, J. (1977). Ibérica. Geografía e Historia de España y de los Países Hispánicos, Barcelona: Vicens Vives.

\section{Libros analizados de LOE de 2. ${ }^{\circ}$ ESO (2008-2010) y 2. ${ }^{\circ}$ Bachillerato (2009)}

\section{2. ${ }^{\circ} \mathrm{ESO}$}

Anaya, 2008: Burgos, M., Muñoz, M. C: $2^{\circ}{ }^{\text {, }}$ Ciencias Sociales, Geografía e Historia, Madrid, Anaya, 2008.

Ecir, 2008: García, E. et alii: Geografía e Historia, 2. ${ }^{\circ}$ ESO, Valencia, Ecir, 2008.

Santillana, 2008: Caballero, J. M. et alii: Geografía e Historia, 2. ${ }^{\circ}$ ESO, Madrid, Santillana-Voramar, 2008.

SM, 2010: Cortes, C., Fernández-Mayorales, J: Ciencias Sociales, Geografía e Historia, 2. ${ }^{\circ}$, Basauri, SM, 2010.

Vicens Vives, 2008: García, M. et alii: Demos. Ciencias Sociales, geografía e historia, Segundo Curso, Barcelona, Vicens Vives, 2008.

\section{2. ${ }^{\circ}$ de Bachillerato}

Anaya, 2009: García de Cortázar, F., Donézar, J. M. ${ }^{a}$, Valdeón, J., Fernández Cuadrado, M., Gamazo, A. (2009), Historia Bachillerato. 2, Anaya, Madrid.

Ecir, 2009: García Almiñana, E. (coord.), (2009), Cereijo, C., Chiquillo, J. A., García, E., Gomis, J. P., Latorre, F., Rey, F., Sebastían, R., Historia de España, 2 Bachillerato, Ecir, Paterna.

Santillana, 2009: Fernández Ros, J. M., González Salcedo, J., León Navarro, V., Ramírez Aledón, G. (2009), Historia de España 2 Bachillerato. Santillana, Madrid.

SM, 2009: Bahamande, A., Otero, L. E., Historia de España, 2. Bachillerato, SM: Madrid. 
Vicens Vives 2009: Aróstegui, J., García Sebastián, M., Gatell, C., Palafox, J., Risques, M., (2009), Historia de España, Vicens Vives, Barcelona.

\section{Libros analizados de LOMCE 2. ${ }^{\circ}$ ESO y 2. ${ }^{\circ}$ Bachillerato (2016)}

\section{2. ${ }^{\circ} \mathrm{ESO}$}

Anaya, 2016: Burgos, M, Muñoz-Delgado, M. ${ }^{a}$ C. (2016). Geografía e Historia, $2 .^{o}$ ESO, Madrid: Anaya.

Santillana, 2016: Grence, T., Gregori, I. (dir.), (2016). Geografía e Historia. 2 ESO, Madrid: Santillana.

Vicens Vives, 2016: García, M, Gatell, C., Riesco, S. (2016), Geografía e Historia. 2. ${ }^{\circ}$ ESO, Barcelona: Vicens Vives.

\section{2. $\quad$ Bachillerato}

Anaya, 2016: García de Cortázar, F., Donézar, J. M., Valdeón, J., Del Val, M. ${ }^{a}$ I., Cuadrado, M. F., Gamazo, A. (2016). Historia de España, Bachillerato.2, Madrid: Anaya

Santillana, 2016: Fernández Ros, J. M., González, J., León, V., Ramírez, G. (2016). Historia de España, Madrid: Santillana.

Vicens Vives, 2016: Álvarez, L., García, M., Gatell, C., Gibaja, J. C., Risques, M. (2016). HE. Historia de España, Barcelona: Vicens Vives.

\section{Nota sobre el autor:}

Jorge Sáiz Serrano es profesor asociado del Departamento de Didáctica de las Ciencias Experimentales y Sociales de la Universidad de Valencia y profesor de educación secundaria en el IES Tirant lo Blanc de Torrent. Es licenciado (1992) y doctor (2003) en Geografía e Historia por la Universidad de Valencia, con premio extraordinario en ambas titulaciones y Doctor en Didácticas Específicas por dicha universidad («Educación histórica y narrativa nacional», 2015). Combina su docencia en secundaria con la formación universitaria de profesorado de Educación Primaria y Secundaria, y forma parte del Grupo Gea-Clío de innovación e investigación en Didáctica de las Ciencias Sociales. Dispone de una trayectoria previa como historiador medievalista aunque en la actualidad su campo prioritario de investigación es la didáctica de las ciencias sociales, en concreto la educación histórica (como enseñanza y aprendizaje del pensamiento histórico) y la construcción de identidades nacionales en manuales escolares y en narrativas de estudiantes y futuros profesores. Los resultados 
de sus investigaciones han sido difundidos en cerca de treinta publicaciones entre artículos en revistas nacionales e internacionales (Revista de Educación, Revista de Estudios Sociales, REDIE. Revista electrónica de investigación educativa, REIFOP. Revista Electrónica Interuniversitaria de Formación del Profesorado, Didáctica de las Ciencias Experimentales y Sociales, Clio, History and History Teaching, Íber Didáctica de las Ciencias Sociales, Investigación en la escuela), así como en comunicaciones y ponencias en congresos en Barcelona, Santiago de Compostela, Murcia y Oporto.

\section{Referencias}

Álvarez Junco, José. Dioses útiles. Naciones y nacionalismo. Madrid: Galaxia Gutteberg, 2016.

- Coord. Las historias de España. Visiones del pasado y construcción de identidad, In Historia de España vol. 12, edited by Josep Fontana and Ramón Villares. Madrid: Marcial Pons, 2013.

ARCHILÉs, Ferran. «Melancólico bucle. Narrativas de la nación fracasada e historiografía española contemporánea». In Estudios sobre nación y nacionalismo en la España contemporánea, edited by Ismael Saz and Ferran Archilés, 245330. Zaragoza: Prensas Universitarias de Zaragoza, 2011.

ARCHILÉs, Ferran, e Ismael SAZ, ed. Naciones y estado. La cuestión española. Valencia: PUV, 2014.

BALIBAR, Etiene. «La forma nación: historia e ideología». In Raza, nación y clase, edited by Immanuel Wallerstein and Etiene Balibar, 135-167. Madrid: IEPALA, 1991.

Barca, Isabel, y M. a Auxiliadora Schmidt. "La consciencia histórica de los jóvenes brasileños y portugueses y su relación con la creación de identidades nacionales». Educatio Siglo XXI 31 (1) (2013): 25-46.

BARTON, Keith. «A sociocultural perspective on children's understanding of historical change: comparative findings from Northern Ireland \& the United States». American Educational Research Journal 38 (2001): 881-893.

- «School History as a Resource for Constructing Identities: Implicacions for Research from the United States, Northern Ireland and New Zeland». In History Education and the Construction of National Identities, edited by Mario Carretero, Mikel Asensio and María Rodríguez Moneo, 93-108. Charlotte CT: IAP, 2012.

BARTON, Keith, y Linda Levstik. Teaching History for the Common Good. Nueva York-Londres: Routledge, 2004. 
Berger, Stephan. «De-Nationalizing History and Nationalizing It Differently! Some Reflections on How to Defuse the Negative Potential of National(ist) History Teaching». In History Education and the Construction of National Identities, edited by Mario Carretero, Mikel Asensio and María Rodríguez Moneo, 33-48. Charlotte CT: IAP, 2012.

- «Narrating the Nation: Historiography and Other Genres». In Narrating the Nation Representations in History, Media and Arts, edited by Stephan Berger, Linas Eriksonas and Andrew Mycock, 1-16. Nueva York-Oxford: Berghahn, 2008.

- «Retorn al paradigma nacional? Lescriptura de la història nacional a Alemanya, Itàlia, França i el Regne Unit del 1945 al present». In La persistència de la nació. Estudis sobre nacionalisme, edited by Ferran Archilés, 101-182. Valencia: PUV, 2015.

Berger, Stephan, y Chris Lorenz. "Introduction». In Nationalizing the Past. Historians as Nations Builders in Modern Europe, edited by Stephan Berger and Chris Lorenz,1-25. Londres: Palgrave McMillan, 2010.

Berger, Stephan, y Christoph Conrad. The Past as History. National Identity and Historical Consciousness in Modern Europe. Londres: Palgrave McMillan, 2015.

Bernal, Antonio M. «Monarquía e imperio». In Historia de España vol. 3, edited by Josep Fontana and Ramón Villares. Madrid: Marcial Pons, 2007.

— «Colonias, imperio y estado nacional». In Historia de las Españas. Una aproximación crítica, edited by Juan Romero and Antoni Furió. Valencia: Tirant Humanidades, 2015.

BНАВНА, Homi. «Introducción: narrar la nación». In Nación y narración. Entre la ilusión de una identidad y las diferencias culturales, edited by Homi Bhabha, 1-11. Madrid: Siglo XXI, 2010.

BILlig, Michael. Nacionalismo banal. Madrid: Capitán Swing, 2014.

CARRETERo, Mario, y Marian KRIGER. «¿Forjar patriotas o educar cosmopolitas? El pasado y el presente de la historia escolar en un mundo global». In Aprender y pensar la historia, edited by Mario Carretero y James Voss, 71-98. Buenos Aires: Amorrortu, 2004.

Carretero, Mario, Mikel Asensio y María Rodríguez Moneo, ed. History Education and the Construction of National Identities. Charlotte CT: IAP, 2012.

Carretero, Mario. Constructing Patriotism. Teaching History and Memories in Global Worlds. Charlotte CT: IAP, 2011.

Elliot, John. Imperios del mundo atlántico. España y Gran Bretaña en América (1492-1830). Madrid: Taurus, 2006.

Foster, Stuart. «Dominant Traditions in International Textbook Research and Revision». Education Inquiry 2 (1) (2011). 
FOSTER, Stuart. «Re-thinking historical textbooks in a globalized world». In History Education and the Construction of National Identities, edited by Mario Carretero, Mikel Asensio and María Rodríguez, 49-62. Charlotte CT: IAP, 2012.

Foster Stuart, y Keith Crawford, eds. What Shall We Tell the Children? International Perspectives on School History Textbooks. Greenwich. Connecticut: IAP, 2006.

FucHS, Eckhardt. «Currents trends in History and Social Studies Textbook Research». Journal of International Cooperation in Education 14 (2) (2011): 17 $-34$.

Furió, Antoni. «Las Españas medievales». In Historia de las Españas. Una aproximación crítica, edited by Juan Romero and Antoni Furió, 77-145. Valencia: Tirant Humanidades, 2015.

GARcía CÁRCEL, Ricardo. Las herencias del pasado. Las memorias históricas de España. Madrid: Galaxia Gutenberg, 2013.

GARcía Fitz, Francisco. La Reconquista. Granada: Universidad de Granada, 2010.

Gómez, Cosme J., y Pedro Miralles. «¿Pensar históricamente o memorizar el pasado? La evaluación de los contenidos históricos en la educación obligatoria en España». Revista de Estudios Sociales 52 (2015): 52-48.

Gómez, Cosme J., Raimundo Rodríguez y Pedro MiRalles. «La enseñanza de la Historia en Educación Primaria y la construcción de una narrativa nacional. Un estudio sobre exámenes y libros de texto en España». Perfiles Educativos XXXVII (150) (2015): 20-38.

Grever, Maria, y Siep StuUrman, ed. Beyond the Canon: History for the 21st century. London: Palgrave Macmillan, 2007.

GuYver, Robert, ed. Teaching History and the Changing Nation State. Transnational and Intranational Perspectives. Londres: Bloomsbury, 2016.

KAMEN, Henry. Del imperio a la decadencia. Los mitos que forjaron la España moderna. Madrid: Temas de Hoy, 2006.

- Imagining Spain. Historical myth and national identity. New Haven y Londres: Yale University Press, 2008.

Kropman, Marc, Carla VAN BoXTel y Janest VAN DrIE. «Small country, great ambitions: Prospective teachers' narratives and knowledge about Dutch history». In Joined-up history: New Directions in History Education Research, edited by Arthur Chapman and Arie Wilschut, 57-84. Charlotte: IAP, 2015.

LEE, Peter. «From National Canon to Historical Literacy». In Beyond the Canon: History for the 21st century, edited by Maria Grever and Siep Stuurman, 1930. London: Palgrave Macmillan, 2007.

LEEuw-Roord, Joke van der, «Two Steps Forward, One Step Back: Shoring Our Stories and Looking for the Common Threads». In Making a Difference: Fif- 
teen years of EUROCLIO, edited by Dean Smart, 66-73. La Haya: EUROCLIO, 2007.

LEEUw-Roord, Joke van der, Ed. History changes. Facts and figures about history education in Europe since 1989. La Haya: EUROCLIO, 2004.

- «Two Steps Forward, One Step Back». In Beyond the Canon: History for the 21st century, edited by Maria Grever and Siep Stuurman. London: Palgrave Macmillan, 2007.

LÉvesque, Stephane, Jean-Philippe Croteau y Raphael GaNI. «Conscience historiques des jeunes francophones d'Ottawa: sentiment d'appartenance franco-ontarienne et récit du passe». Revue du Nouvel-Ontario 40 (2015): 177228.

LÓPEZ FACAL, Ramón. «Identificación nacional y enseñanza de la historia (19702008)». Historia de la Educación 27 (2008): 171-193.

- «La nación ocultada». In La gestión de la memoria. La historia de España al servicio del poder, edited by Juan Sisinio Pérez Garzón et al., 111-160. Barcelona: Crítica, 2000.

LÓPEZ FACAL, Ramón, y Jorge SÁIz. «Spain: History Education and Nationalism Conflicts». In Teaching History and the Changing Nation State, edited by Robert Guyver, 201-215. Londres: Bloomsbury, 2016.

Martínez Millán, José. "La dinastía Habsburgo en la historiografía española de los siglos XIX y XX». Libros de la Corte.es 7 (2013): 33-58.

MuÑoz, Jordi. La construcción politica de la identidad española: ¿del nacionalcatolicismo al patriotismo democrático?. Madrid: CIS, 2012.

PÉrez Garzón, Juan Sisinio. “¿Por qué enseñamos Geografía e Historia? ¿Es tarea educativa la construcción de identidades». Historia de la Educación 27 (2008): 37-55.

- «El nacionalismo español: los resortes de una hegemonía política y cultural». In Pensar històricament. Ėtica, ensenyament $i$ usos de la historia, edited by Marició Janué, 123-145. Valencia: PUV, 2009.

Pérez Vejo, Tomás. España imaginada. Historia de la invención de una nación. Madrid: Galaxia Gutenberg, 2015.

PERIS, Álvar. «Nación española y ficción televisiva. Imaginarios, memoria y cotidianidad». In La nación de los españoles. Discursos y prácticos del nacionalismo español en la España contemporánea, editeb by Ferran Archilés, 392-418. Valencia: PUV, 2012.

PINGEL, Falk. UNESCO Guidebook on Textbook Research and Textbook Revision. Paris y Braunschweig: Unesco \& Georg-Eckert-Institut, 2010.

Repoussi, Maria, y Nicole TutiauX-Guillon. «New Trends in History Textbook Research. Issues and Methodologies toward a School Historiography». Journal of Educational Media, Memory and Society 2 (1) (2010): 154-170. 
Ríos Saloma, Martín. «From the Restoration to the Reconquest: The construction of a national myth (An historiographical review. 16th -19th centuries)». La España medieval 28 (2005): 379-414.

- La Reconquista en la historiografía española contemporánea. Madrid: Sílex, 2013.

- La Reconquista. Una construcción historiográfica (siglos XVI-XIX). Madrid: Marcial Pons, 2011.

RuIz, Pedro. "Los usos de la historia en las distintas maneras de concebir España». In Historia de las Españas. Una aproximación crítica, edited by Juan Romero and Antoni Furió, 27-75. Valencia: Tirant Humanidades, 2015.

SÁIz, Jorge. «¿Hay sitio para la Edad Media en las enseñanzas primaria y secundaria?». In Nuevos temas, nuevas perspectivas en historia medieval, edited by Ester López, 183-214. Logroño: IER, Instituto de Estudios Riojanos, 2015.

- «Actividades de libros de texto de Historia, competencias básicas y destrezas cognitivas, una difícil relación: análisis de manuales de $1 .^{\circ}$ y $2 .^{\circ}$ de ESO». Didáctica de las Ciencias Experimentales y Sociales 25 (2011): 37-64.

- «Alfabetización histórica y competencias básicas en libros de texto de historia y en aprendizaje de los estudiantes». Didáctica de las Ciencias Experimentales y Sociales 27 (2012): 43-66.

- «Educación histórica y narrativa nacional». PhD diss., Universidad deValencia, 2015.

- «La Península Ibérica medieval y las identidades en los actuales libros de texto de historia de 2. ${ }^{\circ}$ de ESO». Íber. Didáctica de las Ciencias Sociales, Geografía e Historia 70 (2012): 67-77.

SÁIz, Jorge, y Isabel BARCA. «Students narrating their nation. Models of national narratives of Spanish and Portuguese students». London Review of Education (en prensa).

SÁIz, Jorge, y Neus Colomer. "La historia moderna peninsular en narrativas de estudiantes al finalizar la ESO». In La Edad Moderna en Educación Secundaria. Experiencias de investigación, edited by Francisco García, Cosme J. Gómez and Raimundo Rodríguez, 155-167. Murcia: Editum, 2016.

SÁIz, Jorge, y Carlos FuSTER. «Memorizar historia sin aprender pensamiento histórico. Las PAU de Historia de España». Investigación en la escuela 84 (2014): 46-57.

SÁIz, Jorge, y Cosme J. GómEz. «Investigar el pensamiento histórico y narrativo en la formación del profesorado: fundamentos teóricos y metodológicos». Revista Electrónica Interuniversitaria de Formación del Profesorado 19 (1) (2016): 175-190. 
SÁIz, Jorge, y Ramón LóPEz FACAL. «Competencias y narrativas históricas. El pensamiento histórico de estudiantes y futuros profesores». Revista de Estudios Sociales 52 (2015): 87-101.

- «Narrativas nacionales históricas de estudiantes y profesorado en formación». Revista de Educación 374 (2016): 118-141.

- «Narrativas nacionales y competencia histórica entre futuros maestros de Educación Primaria en España». Arbor (en prensa, 2017).

SANT, Edda, et al. "How do catalan students narrate the history of Catalonia when they finish Primary Education». McGill Journall of Education 50 (2/3) (2015): 341-362.

SAZ, Ismael, y Ferran ARchILÉs, ed. La nación de los españoles. Discursos y prácticos del nacionalismo español en la España contemporánea. Valencia: PUV, 2012.

SKEY, Michael. National Belonging and Everyday Life. The Significance of Nationhood in an Uncertain World. Basingstoke: Palgrave Macmillan, 2011.

StuUrman, Siep, y Maria Grever, «Introduction: Old Canons and New Histories». In Beyond the Canon: History for the 21st century, edited by Maria Grever and Siep Stuurman, 1-18. London: Palgrave Macmillan, 2007.

Symcox, Linda, y Arie WiLschut, ed. National History Standars. The problem of the canon and the future of teaching History. Charlotte, NC: IAP, 2009.

- «Introduction». In National History Standars. The problem of the canon and the future of teaching History. International review of History education, edited by Linda Symcox and Arie Wilschut, 1-11. Charlotte: IAP, 2009.

TAIBO, Carlos. Nacionalismo español. Esencias, memorias e instituciones. Madrid: Libros de la Catarata, 2007.

- Sobre el nacionalismo español. Madrid: Libros de la Catarata, 2014.

TutiauX-Guillon, Nicole. «A Tradicional Frame for Global History: The Narrative of Modernity in French Secondary School». In History Education and the Construction of National Identities, edited by Mario Carretero, Mikel Asensio and María Rodríguez Moneo. Charlotte CT: IAP, 2012.

VALLS, Rafael. Historiografía escolar española: siglos XIX-XXI. Madrid: UNED, 2007.

- La enseñanza de la Historia y textos escolares. Buenos Aires: Zorzal, 2008.

- La interpretación de la Historia de España y sus orígenes ideológicos en el bachillerato franquista: 1938-1953. Valencia: ICE, 1984.

WERTSCH, James V. «Specific narratives and schematic narrative templates». In Theorizing historical consciousness, edited by Peter Seixas, 49-62. Toronto: University of Toronto Press, 2004.

- Voices of Collective Remembering. Cambridge: Cambridge University Press, 2002.

ZaJDA, Joseph, ed. Nation Building and History Education in a Global Culture. Nueva York-Londres: Springer, 2015. 